\title{
Research and Practice of University Students' Crowdsourcing Strategy in Automotive Fixture Design
}

\author{
Qiang $\mathrm{Yu}^{1,}$, Wencai $\mathrm{Wu}^{1, \mathrm{~b}}$, Qiu $\mathrm{Li}^{1, \mathrm{c}}$ and Shikuan Wang ${ }^{1, \mathrm{~d}}$ \\ ${ }^{1}$ School of Mechanical Engineering, Tianjin University of Technology and Education, Tianjin 300222; \\ ayuqiang95@yeah.net, b1126466131@qq.com, cqiuli_tj@qq.com, d809651276@qq.com
}

Keywords: Crowdsourcing; Automotive Fixture; Entrepreneurship; Internet.

\begin{abstract}
The welding fixture is important equipment in the production of automobile vehicles. And it has a huge demand. This paper studies the business opportunities of the campus crowdsourcing model in the design of automotive fixtures, and the entrepreneurial practice by students in the crowdsourcing model is done. Through the project's development process, it can be found that the crowdsourcing model can be applied to the automotive fixture design process, students learn the actual fixture design skills, and entrepreneurial and employability are enhanced. At the same time the enterprises have significantly reduced the cost of employing personnel. The companies can focus on their energy on the development of new technologies with students' crowdsourcing work. At present, students and a number of automotive fixture companies jointly carried out fixture design crowdsourcing work. The public announce and distributions of design tasks, financial settlements are carried out through the network contract platform. The project has attracted more and more university students and enterprises to participate in the program. The project has a good development trend and has become a good market prospect and activity suitable for students.
\end{abstract}

\section{Introduction}

With the acceleration of automobile retrofitting, the production methods of automobile panels have been continuously updated. Weld fixtures have evolved from traditional mechanical manual fixtures into automated welding fixtures that integrate mechanical, hydraulic, pneumatic, electrical and computer control. At present, the production cycle of prototype automotive to new automotive has been shortened from 5 years to 3-4 years, and the design and manufacturing cycle of welding lines and welding fixtures has been shortened from 1 year to 4-6 months, so the higher requirements on the design and manufacture of welding fixtures is presented. In addition, the cost of welding fixture design and manufacturing can account for up to $20 \%$ of the whole cost of the entire manufacturing system. The life cycle shortening and high design and manufacturing costs increase the cost in the development of new automotive models. All kinds of countermeasures cannot fundamentally solve this problem. At the same time, automotive fixture manufacturers cannot recruit graduates with certain automotive fixture design experience, and the rapid development of the fixture industry is limited.

At this stage, with the rapid growth of the global sharing economy, innovation and entrepreneurship services based on the Internet and other methods are also booming. Crowdsourcing method can both solve problems quickly and efficiently, but also significantly reduce the cost of the company [1,2]. And it is concerned in just a few years. Crowdsourcing is actively developed and can increase employment. With the help of the Internet and other means, the tasks traditionally performed by specific companies and institutions are divided among all voluntary companies and individuals to maximize the use of public power and to achieve greater efficiency [3]. The low cost meets the demand for production and opens up new ways to integrate wisdom, innovation, convenient entrepreneurship, and flexible employment.

This article focuses on the automotive fixture design industry, based on the Internet and crowdsourced service model, with college mechanical sophomore and third grade students as the main body. The integration of production and teaching resources for automotive fixture design is studied. This study on the one hand is to provide students the training opportunity, project practice, and work-study in university. On the other hand the crowdsourcing helps the companies to expand their production capacity, cultivate 
reserve talents. The article mainly researches on improving the level and effectiveness of production-teaching integration in the automotive fixture design field.

\section{Crowdsourcing Entrepreneurial Opportunities of Automotive Fixture Design}

Crowdsourcing is a distributed work task resolution and production model. Work tasks are disseminated through open tenders to unknown, unspecified solutions to job task plan providers [4]. There are many non-learning hours for university students during their studies. Many work study students help themselves in order to improve their economic conditions or increase their practical ability. The crowdsourcing model provides students with the opportunity to work in fragmentary time on campus. At the same time it embodies the advantages of crowdsourcing, which is to take into account the economic efficiency, time efficiency and staff efficiency for both the company and students.

Crowdsourcing has broken through the restrictions on space, industry, and professionalism of traditional automotive fixture design companies. Students who undertake design tasks can choose their own tasks according to their own schedule and level of knowledge. For small and medium-sized enterprises within a limited cost, the mode of crowdsourcing has enabled companies to develop rapidly.

Crowdsourcing inspires the standardization of the automotive fixture design industry, And provides a viable division of labor model and standard for the practice of a new innovative idea in the Internet age [5, 6]. It can inspire new network organization characteristics, change the traditional automotive fixture research and development, design and other innovative activities. Through the crowdsourcing network, potential partners are closely surrounding the company.

The development of Internet technology has promoted the open and non-boundary advantages of crowdsourcing model. Crowdsourcing model help companies to achieve the advantages of their own innovation and R\&D strength combined with the students' professional and time characteristics, as well as the company's own advantages $[7,8]$.

\section{Entrepreneurship Practice of Automotive Fixture Design Based on Crowdsourcing Mode for University Students}

The concept of rowdsourcing in automotive fixture design actually stems from the reflection on the innovative model of fixture design processes. The design of crowdsourcing for automotive fixtures is based on the external force model to achieve the management task of designing human resources. In the early stage enterprises still need to solve problems such as intellectual property rights, business confidentiality, project division of labor, pricing strategy, cost and command control, etc. [9]. Crowdsourcing has long been not a simple change in the development and application of the Internet and not just a matter of business but a profound social change [10]. A large number of facts have proven that the crowdsourcing of the Internet has a major impact on the entrepreneurial practice for college students and will provide new opportunities for college students' entrepreneurial activities.

Especially in the area of intellectual services, such as the fixture design mentioned in this article, college students in the field of fixture design services to establish service-oriented companies should give full play to their own advantages in the field of knowledge related to mechanical design. The work should be selected with suitable work time and ability characteristics for students. On the other hand, college students can make full use of their resources or professional background to achieve their own entrepreneurial goals.

In terms of specific project operations and the early stage of the project, the crowdsourcing project leader promoted the students of material forming and control engineering and mechanical manufacturing. At first about 30 students of grade 2 and 3 were recruited. The students were trained through corporate visits, study and training, and assessment. The first group of team members began to receive the official mission of the company. In the later period, the number of team members will be increased by means of open recruitment within the school, recommendation of team members, etc. And more than two automotive fixture companies will be served. 
In terms of profit model, the first the fixture design fee is the main source of income which is the corresponding design fee of the design of fixtures for three-dimensional and two-dimensional drawings for the enterprise. The second fee is the membership training fee that the newly added team members can pay. Design training is provided for them. And the members who pass the assessment can provide job opportunities in campus. And the third is targeted training fees for companies. The graduates who meet the actual production needs can be trained.

In terms of scale operation and later stage of the project, the first university of fixture design crowdsourcing is a starting point and will develop 2-3 universities and more fixture design companies. In the future a campus crowdsourcing entrepreneurship association can be formed with a scale of 100 students. The association can form a personnel advantage and expand profitability.

\section{The Enlightenment of Undergraduates' Crowdsourcing Mode for Automotive Fixture Design}

Many college students have always talked about entrepreneurship. There is a certain gap between entrepreneurial planning and reality. Market expectations are mostly over-optimistic, and entrepreneurial ideas, thinking, and methods are not recognized by the market. The real business outlook is very poor. Students participating in the crowdsourcing entrepreneurship project can use the social labor supply and demand platform, teachers' cooperative enterprises, etc. to reduce the problems of the college students' own knowledge, experience and ability limitations and solve the problem of less entrepreneurial cooperative enterprises.

The concept and method of crowdsourcing is a certain reference for the entrepreneurial activities of college students. For example, for the beginning of the automotive fixture design entrepreneurship, the newly-started new innovative enterprise may not need special recruiters and special office space to facilitate the savings of operating costs. At the same time, it can also integrate the crowdsourcing platform into the interior of new ventures, breaking through the restrictions of fixed work locations and working hours.

The automotive fixture design innovation and entrepreneurial enterprise decomposes the large workload into a number of small workload task models, and completes the automotive fixture design task through campus crowdsourcing on the network. It will greatly increase the operating efficiency and reduce the overall project cost. Entrepreneurs in the Internet era can rely more on the crowdsourcing model to create a crowdsourcing information center for automotive fixture design through the Internet, establish information sharing mechanisms, and establish incentives for knowledge contributions, and can re-examine their own automotive fixture design business processes. Design work is managed according to the difficulty classification and level of design classification. The crowdsourcing has a natural cost advantage and can greatly reduce the cost of human resources on campus entrepreneurial organizations.

The automotive fixture design entrepreneurs have changed from resource owners to resource integrators. For start-ups, the operating costs can be reduced by eliminating the need for specialized design recruiters and setting up a dedicated office space. Entrepreneurs can integrate their internal and external fixtures design resources, build fixture design service operation mechanisms, and form sustainable profitable venture solutions and financial management solutions. At the same time, it can also integrate the campus crowdsourcing platform into the interior of new start-ups, break through the constraints of fixed work places and working hours. And more importantly, SMEs should break down the task of large workload into tasks with small workloads. The method is completed through campus crowdsourcing on the network, which will greatly increase the efficiency of operations and take into account the dual requirements of time efficiency and economic efficiency. A new network crowdsourcing platform for fixture design can be established. For improving the efficiency of fixture crowdsourcing, the establishment of a fixture design new network crowdsourcing platform is a relatively good solution. Through the form of similar socialized resource aggregation, the power of many netizens is gathered. Entrepreneurs will receive funds and eventually implement the project. 
In the specific operation of the crowdsourcing team, after nearly a year's exploration, the following experience has been gained at this stage: The crowdsourcing project is suitable for university undergraduate students in the second and third grade machinery and related majors. And it is beneficial to students. During study stage in university, students can learn stably and further improve their skills. Students complete work in campus and do not miss normal learning. Work time and place are also flexible. And the activities can further dock with professional courses and improve students' practical ability and employability. It also enable students to obtain work experience and opportunities for work-study work, training skills, getting paid, and increasing enthusiasm. The critical automotive fixture design talents are accumulated for the industry. When students graduate the students can become network engineers and continue to work part-time in this project.

\section{Conclusions}

Undergraduate entrepreneurship is a complicated process. For this article, it is necessary for the fixture design student entrepreneurs to have a certain amount of accumulated professional knowledge, but also to combine their own actual characteristics, flexible use of crowdsourcing model to support innovation and entrepreneurial activities. For the automotive fixture design company, the work tasks which were completed by the internal employees of the organization or the external contractors of the organization now can be divided and distributed to the campus crowdsourcing team in a voluntary and free manner to complete the fixture design works with the crowdsourcing model. The operating costs of the company is reduced and high efficiency in a timely manner is created. And it has a production and operation system with the core competitiveness of technology. The related research and practical experience of university students' automotive fixture design strategy for crowdsourcing have certain reference value for follow-up student entrepreneurial activities.

\section{Acknowledgment}

This work was supported by the Training Plan for Young and Middle-aged Backbone Talents of Tianjin Universities and Colleges, the Science Research and Development Foundation of Tianjin University of Technology and Education, Tianjin undergraduate Innovation and Entrepreneurship Training Program, Mechanical Engineering Institute Me+ Maker Space Project of Tianjin University of Technology and Education Tianjin, China under Grant RC180204, KJ1809, 201810066008, 20172301 respectively.

\section{References}

[1]. Yu Dunhui, Zhang Lingli, Fu Cong, "Online Task Allocation of Spatial Crowdsourcing Based on Dynamic Utility,” Journal of Electronics \& Information Technology. Beijing, Vol. 40, pp.1-8, May 2018.

[2]. Huang Jieping, Cao Anqi, "Behavioural Motivation and Incentive Mechanism of the Public Participation in Knowledge Crowdsourcing," Journal of Beijing Institute of Technology(Social Sciences Edition). Beijing, Vol. 20, pp.88-96, Jul. 2018.

[3]. Wang Zhi-Hong, Fu Chang-Tao, LI Yang-yang, "Research review on the industrial application of crowdsourcing,” Journal of Chang'an University (Social Science Edition). Xi’an, Vol 19, pp.68-76, Sep. 2017.

[4]. Huang Feng, “The Enlightenment of Internet Crowdsourcing to the Innovation of Modern Business Management Mode and Its Application,” Management \& Technology of SME. Shijiazhuang, Vol. 4, pp.55-57, 2018. 
[5]. Xia En-Jun, Zhao Xuan-Wei, "Research on the Factors Affecting Participation Behavior in Crowdsourcing System,” R\&D Management. Shanghai, Vol. 29, pp.18-21, Feb. 2017.

[6]. Cheng Youming, Wu Ying, Gong Bengang, etc., "Crowdsourcing: an operating mode of cloud manufacturing,” Computer Integrated Manufacturing Systems. Beijing, Vol. 23, pp.1167-1175, Jun. 2017.

[7]. Yan Jie, Liu Renjing, Liu Han, "A Literature Review of Domestic and Foreign Crowdsourcing Research,” Forum on Science and Technology in China. Beijing, Vol. 8, pp.59-68, August 2017.

[8]. Dong Kunxiang, Hou Wenhua, Xie Zongxiao, Zhen Jie, "The evolution path and future direction of crowdsourcing study between domestic china and overseas,” Science \& Technology Progress and Policy. Wuhan, Vol. 33, pp.154-160, Apr. 2016.

[9]. Liu Xiaoli, "Research of User-decision Crowdsourcing and its Implementation for SMEs of China: Innovation and Resources Optimization,” Journal of Yanshan University (Philosophy and Social Science Edition). Qinhuangdao, Vol. 18, pp.76-82, Sep. 2017.

[10]. Lin Sufen, Lin Feng, “A Research on the Definitions and Models of Crowdsourcing and Their Future Development,” Science and Technology Management Research. Guangzhou, pp.212-217, Vol. 4, 2015. 